\title{
New era of diet therapy and research including Low Carbohydrate Diet (LCD)
}

\author{
Koji Ebe ${ }^{1,2}$, Hiroshi Bando ${ }^{2,3}$ \\ ${ }^{1}$ Takao Hospital, Kyoto, Japan \\ 2 Japan Low Carbohydrate Diet Promotion Association, Kyoto, Japan \\ ${ }^{3}$ Tokushima University / Medical Research, Tokushima, Japan
}

Corresponding Author: Hiroshi Bando, MD, PhD, FACP

Address: Tokushima University /Medical Research, Nakashowa 1-61, Tokushima 770-0943, Japan; TEL: +81-90-3187-2485.

Received date: 11 November 2018; Acceptance date: 11 November 2018; Published date: 15 November 2018.

Citation: Koji Ebe, Hiroshi Bando, "New era of diet therapy and research including Low Carbohydrate Diet (LCD)", Asp Biomed Clin Case Rep, vol.2, no.s1: 1-3, 2018.

Copyright () 2018 Koji Ebe, Hiroshi Bando. This is an open access article distributed under the Creative Commons Attribution License, which permits unrestricted use, distribution, and reproduction in any medium, provided the original work is properly cited.

\section{Key words:}

Low Carbohydrate Diet (LCD); Calorie Restriction (CR); National Integrated Project for Prospective Observation of Non-communicable Disease And its Trends in the Aged (NIPPON DATA); Prospective Urban Rural Epidemiology (PURE); Japanese LCD Promotion Association (JLCDPA).

\section{Special Issue on Low Carbohydrate Diet (LCD):}

The role of this journal, "Asploro Journal of Biomedical and Clinical Case Reports (AJBCCR)" would be providing meaningful information on medical practice and research widely in the world. The word ASPLORO means Research which is coined from the language Esperanto. In the special issue concerning diet therapy, various research and case reports will be expected such as Low Carbohydrate Diet (LCD), Calorie Restriction (CR) Diet, the Mediterranean Diet, and other kinds of methods.

What are the trends in health situation and problems worldwide ?. There have been increasing of Non-Communicable Diseases (NCD) in developed and developing countries, such as metabolic syndrome, obesity, hyperlipidemia and diabetes [1]. Especially, increased prevalence of diabetes has been medical and also a social problem. Then, useful and effective nutritional therapy would be crucial therapy as the basal treatments for these diseases [2].

In the point of clinical practice, the management for diabetes has been argued for long concerning the diagnosis, treatment and adequate nutritional therapy. There have been recent controversies on the discussion about recommended goal of the $\mathrm{HbA} 1 \mathrm{c}$ value. They include several diabetic societies, American Diabetes Association (ADA) and International Diabetes Federation (IDF) and American College of Physicians (ACP) $[3,4]$. Consequently, adequate and applicable control of diabetic variability has been crucial for future diabetic management .

As to diet therapy, LCD was initiated by two known researchers who are Atkins and Bernstein in European and North American 
regions [4,5]. After that, LCD has been rather popular and recognized as an effective diet method. The effect of LCD has been accepted for many people in comparison of CR. After that, Shai et al. reported the comparison of LCD, CR, and Mediterranean Diet, which became the milestone of LCD [6]. By the exchange of carbohydrate food with greater intake of protein or fat, there observed remarkable clinical effect . Furthermore, LCD brought continuous weight reduction in short-term and long-term [6]. In contrast, there have been conflicting and incomplete results for long-term clinical influence for health outcomes. Besides them, from metaanalyses research such as large cohort studies, the possible relationship has revealed between low carbohydrate intake and elevated mortality rate [7].

As to diet therapy, isocaloric meal after 10$15 \%$ of weight reduction brought a decrease of Resting Energy Expenditure (REE) and Total Energy Expenditure (TEE) [8]. These degrees of the diets were the greatest in the low-fat, intermediate in the low-glycemic index, and the least in the very LCD [8]. There was a megastudy of NIPPON DATA (National Integrated Project for Prospective Observation of Noncommunicable Disease And its Trends in the Aged) from more than 13000 subjects [9]. Among these data, moderate diets lower in carbohydrate and higher in protein and fat were significantly inversely associated with CVD and total mortality in women [9].

As recent mega-study, the 2017 Prospective Urban Rural Epidemiology (PURE) study has been known and reliable. Data were from 18 countries in five continents with 7.4 years in the median of more than 130 thousand subjects. As a result, high carbohydrate intake was observed with an elevated risk ratio of mortality [10]. These data may influence the discussion of LCD and some nutritional guidelines .

As mentioned above, LCD has developed in Western countries. In contrast, Ebe has started LCD in Japan, who is our research collaborator group. Consecutively, authors have developed various trials of practice and research for long. There are various research themes, such as i) effect of weight reduction in thousands of patients, ii) blood glucose profile a day and Morbus (M) value compared with $C R$ and $L C D$, iii) hyperketonemia due to $L C D$, iv) increased values of ketone bodies (KB) in the axis of fetusplacenta-newborn-mother indicating apparently physiological role of KB, v) Meal Tolerance Test (MTT) on $70 \mathrm{~g}$ of carbohydrate on CR breakfast, and so on [11-13].

Among these, $M$ value was especially proved to be clinically useful and significant for the blood glucose profile and variability between LCD and CR [11].

LCD has been useful for lots of patients with diabetes, obesity and metabolic syndrome in the primary setting because we have proposed a simple and effective LCD formula. They are super-LCD, standard-LCD and petit-LCD, in which the carbohydrate ratio per calorie intake is $12 \%, 26 \%$ and $40 \%$, while traditional CR is $55-$ $60 \%$. Using these three types of LCD, many patients could improve their diabetic states and reduce enough weights in our clinical study.

Authors have continued clinical practice and research for LCD for years. Furthermore, we have developed a medical and social movement of LCD. Ebe and colleagues have established Japanese LCD Promotion Association (JLCDPA) in 2013, and developed our activities as follows: i) Beneficial information of LCD on website concerning 77 affiliated hospitals and clinics so far, ii) Biannual journal about LCD, and frequent mail magazine dissemination, iii) Seminars and workshops have continued for years, including 11 seminars and 19 cooking workshops in large cities in the last 2 years.

As to definition of LCD, Bernstein and Feinman proposed the guidelines in the following: i) Very low-carbohydrate ketogenic diet (VLCKD), ii) Low-carbohydrate diet: $<130 \mathrm{~g} / \mathrm{d}$ or $<26 \%$ total energy, iii) Moderate-Carbohydrate Diet: $26 \%-45 \%$, iv) High-Carbohydrate Diet: $>45 \%$ [14]. The Systemic review was reported 
concerning diet therapy [15]. It includes 9 kinds of diet way, which are LCD, High-protein diet, Mediterranean diet, vegetarian diet, low-fat diet, DASH-diet, Paleo diet, Low-glycemic index/load diet and control diet.

In summary, we described the topics concerning diet therapy, such as LCD, CR and other methods. As this article becomes the initiator, we expect lots of remarkable papers and opinions will come associated with further significant discussion and development.

\section{References:}

[1] NCD Risk Factor Collaboration (NCD-RisC), "Worldwide trends in diabetes since 1980: a pooled analysis of 751 population based studies with 4.4 million participants". Lancet Lond Engl 2016, vol.387, no.10027: 1513-30, 2016.

[2] Ogurtsova K, da Rocha Fernandes JD, Huang $Y$, et al., "IDF Diabetes Atlas: Global estimates for the prevalence of diabetes for 2015 and 2040". Diabetes Res Clin Pract, vol.128: 40-50, 2017.

[3] American Diabetes Association, "Pharmacologic Approaches to Glycemic Treatment: Standards of Medical Care in Diabetes-2018". Diabetes Care, vol.41, Suppl.1:S73-S85, 2018.

[4] Atkins RC, "Dr. Atkins' diet revolution". Bantam Books, New York: ISBN-10: 0553271571, ISBN-13: 978-0553271577, 1981.

[5] Bernstein RK, "Dr. Bernstein's Diabetes Solution". Little, Brown and company, New York: ISBN 10: 0316093440, ISBN 13: $9780316093446,1997$.

[6] Shai I, Schwarzfuchs D, Henkin Y, et al., "Weight loss with a low-carbohydrate, Mediterranean, or low-fat diet". N Engl J Med, vol.359: 229-41, 2008.

[7] Noto H, Goto A, Tsujimoto T, et al., "Lowcarbohydrate diets and all-cause mortality: a systematic review and meta-analysis of observational studies". PLoS One, vol.8, no.1: e55030, 2013.

[8] Ebbeling CB, Swain JF, Feldman HA, et al.,
"Effects of dietary composition on energy expenditure during weight-loss maintenance". JAMA, vol.307, no.24: 2627-34, 2012.

[9] Nakamura Y, Okuda N, Okamura T, et al., "Low-carbohydrate diets and cardiovascular and total mortality in Japanese: a 29-year follow-up of NIPPON DATA80". Br J Nutr, vol.112, no.6: 916-24, 2014.

[10] Dehghan $M$, Mente A, Zhang $X$, et al., "Associations of fats and carbohydrate intake with cardiovascular disease and mortality in 18 countries from five continents (PURE): a prospective cohort study". Lancet, vol.390, no.10107: 2050-62, 2017.

[11] Bando H, Ebe K, Muneta T, et al., "Effect of low carbohydrate diet on type 2 diabetic patients and usefulness of M-value". Diabetes Res Open J, vol.3, no.1: 9-16, 2017.

[12] Muneta T, Kagaguchi E, Nagai $Y$, et al., "Ketone body elevation in placenta, umbilical cord, newborn and mother in normal delivery". Glycative Stress Research, vol.3, no.3: 133-40, 2016.

[13] Ebe K, Bando H, Yamamoto K, et al., "Daily carbohydrate intake correlates with $\mathrm{HbA} 1 \mathrm{c}$ in low carbohydrate diet (LCD)". J Diabetol, vol.1, no.1: 4-9, 2017.

[14] Feinman RD, Pogozelski WK, Astrup A, et al., "Dietary carbohydrate restriction as the first approach in diabetes management: Critical review and evidence base". Nutrition, vol.31, no.1: 1-13, 2015.

[15] Schwingshackl L, Chaimani A, Hoffmann G, et al., "Impact of different dietary approaches on glycemic control and cardiovascular risk factors in patients with type 2 diabetes: a protocol for a systematic review and network meta-analysis". Syst Rev, vol.6, no.1: 57, 2017.

\footnotetext{
Key words: Low Carbohydrate Diet (LCD); Calorie Restriction (CR); National Integrated Project for Prospective Observation of Non-communicable Disease And its Trends in the Aged (NIPPON DATA); Prospective Urban Rural Epidemiology (PURE); Japanese LCD Promotion Association (JLCDPA).
} 